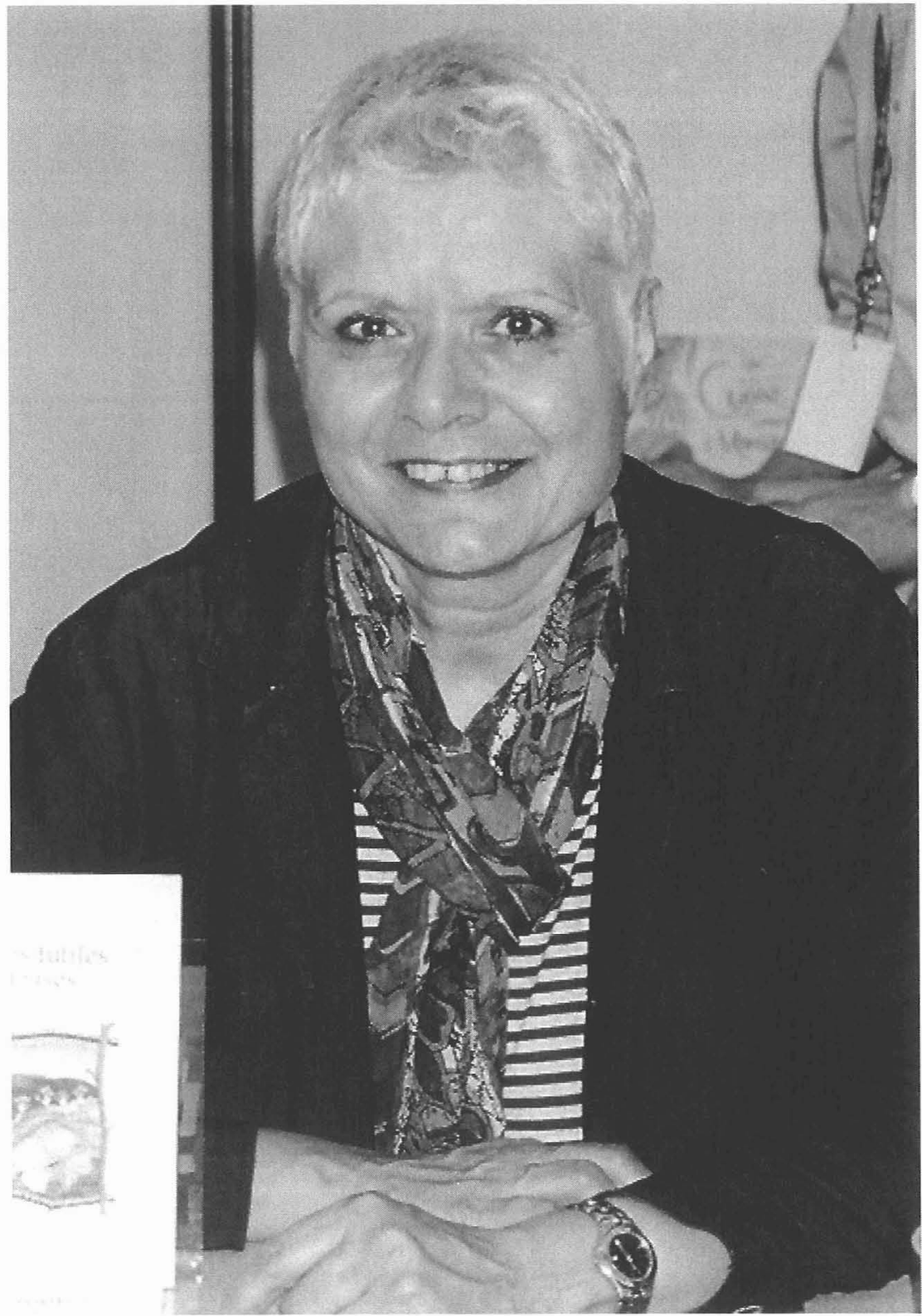

Jeanine Baude 
Jeanine Baude a publié plus d'une quinzaine de recueils de poèmes dont Le bol du matin (Tipaza, 2001), C'est un tango (L'Arbre à paroles, 2001), Dans le parc (L'Arbre à paroles, 2000), Un bleu d'équinoxe (Éditions AB, 2000), Vbratislave (Encres vives, 1999), Incarnat Désir (Rougerie, 1998), C'était un paysage (Rougerie, 1992). Elle a dirigé ou préfacé plusieurs anthologies et numéros de revues littéraires.

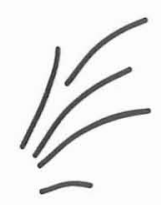

\section{NEIGES SUR NEW YORK}

Ta neige anime la fenêtre. Le pont de Brooklyn s'alourdit. Les oiseaux $L$ ramassés, en grappe, ourlent les fontaines. Il y eut un moment de silence avant - my heart is broken - puis la neige est venue coudre l'horizon. Le chemin se faisait, dans le temps, avec malles et paniers depuis la descente du bateau jusqu'à ce point d'horizon cousu à la frontière du parc et de la ville. Là, où je suis - now, broken - ils déposaient le peu de victuailles et de trésors, leurs corps fatigués.

Milliers d'aigrettes à la fenêtre dansent. Cantate pour piano et violoncelle sur les robes, les bonnets enfoncés jusqu'aux oreilles, ces femmes vont. Où vont-elles depuis? Lîle encore se débat. Sur les murs l'odeur se devine. Une femme puis l'autre. On dévisage. Ce n'est que l'histoire qui passe sous les jupes. 
Ca peut faire mal. Gravats lourds à porter. Regardez la ville qui se construit et se construit encore. Les mains gercées ont tellement écrit que les pierres suintent. L'encre se lit aux encoignures, sur les piliers. La ferraille partout rongée. Cela fait couleur sang une musique.

D eut-être ce couple, sur le pont, écoute. Visages radieux des premiers 1 arrivants et des amants qui traînent alors que je me presse. Le bus s'en va. J'aurai le suivant. Eux aussi attendaient cette occasion qui ne vient pas. La lune assure que les filins tiennent bon. La vie conduit quelque part. Chaque amant, chaque solitude se ramasse comme les oiseaux - non pas autour des fontaines - mais plus haut, sans savoir où. 
Ca s'étire : les longues jambes jusqu'à l'océan, les bras vers le ciel. Un corps, une ville, une étrange composition totalement imaginée par l'homme blanc. Le peau-rouge lui vendit pour vingt-quatre dollars cette boue, ces collines, ce fleuve. Etrange transaction si l'on sait que pour un indien la terre ne nous appartient pas. Seulement prêtée le temps d'une vie et ainsi de génération en génération. L'homme noir, ce fut une autre histoire. Le vent se glisse entre les tours, avec fracas. Il raconte: New York is black, New York is red, New York is yellow.

'est à peu près cela quand on marche dans la ville à en perdre son âme. Le corps écoute tous les corps. Cela s'entend. J'ai les oreilles brûlées par le bruit que fait le temps, l'Histoire. - Nightmare - Ils sont fiers de cette ville qui ne dort jamais. - Cauchemar - 
I e soleil passe sur la neige. Etreint le blanc, le dissout. La vapeur d'eau L colore les jambes des femmes. L'agitation n'a de cesse. Busisnessmen, students, homeless, homeless, students, businessmen, students, homeless passing by and passing way Dans le froid de l'hiver ou la chaleur qui tue c'est le rythme quil faut prendre et scander : passing by and passing way, someone something, passing by and passing way, something somebody, do you want some coffee? Do you want a cup of tea? Do and do and do and do. Faire, défaire le fil de la trame. Combien tu vaux? Eh! Dollar???? And do and do and do and do

I a fonte des piliers repeints. Le gris. Le noir. L'usure. Le froid. La 1 femme nue ou presque sur les marches. On a envie de la caresser. O solitude. La femme brisée. Siffle, sifflements, siffler, entre les tours, le vent. La femme nouée. La couverture pue l'humidité. Ravages. A ghost. Fantasmer sa vie. 
u l'écrive là dans un silence quion ne suppose pas. Qui existe. Perles de fureur et de fracas. Dans ce silence là. Inhabité pour beaucoup mais si présent. A en crever les tympans. Dans le labyrinthe se diriger vers cette obscurité qui répond. Répandre les cailloux, le souffle. Tous les déshérités ont un caillou dans leur poche.

$F^{t}$ je miarrête. Comme ressurgit de l'intérieur du cratère cette parole emmaillotée dans les braises. Y arriver, peut-être. Ce serait alors crier le pourquoi et le comment, le blanc des mots. Regarder la phrase descendre, se couler sur les roches. 
$F^{t}$ la ville poursuit. Lave perpétuelle. Locéan tout en bas berce cette 1 lumière. C'est lit gigogne pour le poème. L'Histoire, râtelier, mangeoire ou dentier nourrit et muselle, se porte à découvert, en sarrau. Les rues, les plaies.

Revenir sur le cristal d'une fenêtre. S'abreuver, le front contre la vitre. 
Y croire. Marcher dans la rumeur. Affronter.

Ce lys blanc; cette orchidée. Tu devines une impossible demeure. Le corps, tu le prends à témoin.

Le voyage amoureux. La fin des temps. 
Ce dégagement dans le texte, venu on ne sait pas très bien pourquoi, t'apprend à regarder.

Le blanc s'égarer.

La chrysalide, la feuille du mûrier sur le givre du puzzle. L'angle de l'emboîtement. Le récit, oeil crevé, mais regarder où? Trace.

New York, février 2003 